contributors. The editors criticize the first book on grounds of expense, and this book is a courageous attempt to reduce cost by the 'economy' standard of its production, and by virtually abolishing illustrations.

Such an attempt, however, is bound to be fraught with difficulties, and it must be confessed that this is rather an odd book. Its $\mathbf{4 4 0}$ pages of text are subdivided into a very large number of small essays with no attempt at grouping under common headings by system. The result is a volume, more readable than most text-books, but disconcertingly haphazard for the undergraduate at whom it is largely aimed. One feels that a little co-ordination and fusion of the many separate sections would produce a much more coherent book.

The question of format, however, is less important than that of content and balance, and this is where the book is most open to criticisms. A few instances will suffice. The section on rare muscular disorders is given almost as much space as the whole of the respiratory tract; coeliac disease and fibrocystic disease of the pancreas are together granted only half a page; and, surely, in a book designed to cover tropical paediatrics, there is something wrong when kwashiorkor is dismissed in one page, and the whole of infant feeding, nutritional disorders and vitamin deficiencies are given less space than the much rarer disorders of the endocrine glands. Whilst, too, it is quite legitimate, though perhaps unwise, to dispense with illustrations in a book of this sort, one wonders what purpose is served by including 13 only, four of them on one disease.

Taken individually, many of the sections are admirable. But the preface states the aim of the book as one "which covers all or most aspects of child care as those appear in this part of the world, which includes the total field of paediatrics as taught in the West, and many other problems which are of little or no importance there'. This would be a very large claim for a much larger book, and is far from being realized here.

In its present form it is difficult to recommend this book as the sole paediatric text-book for undergraduates. But if in future editions the editors would expand those parts dealing with the tropical and preventive aspects, especially as they apply to South-East Asia, and reduce somewhat those sections on general paediatrics which are dealt with more fully in other books, the book would establish itself as a useful and interesting companion to a new and important subject.

\section{Le Bien-Etre de L'Enfant en Afrique au Sud du Sahara.} By Maurice Gaud. (Pp. 186.) Published by the Centre International de L'enfance, Lagos. 1959.

The publication commemorates and, to some extent, reports the proceedings of a six-day congress covering an immense field which was held in Lagos in March, 1959, under the Chairmanship of Professor Robert Debré. Delegates from European countries with African interests joined representatives from the territories themselves, the majority of whom held some administrative post. The participants are categorized in the preface as sociologists, ethnologists, agronomists, psychologists, physical anthropologists, educators and specialists - in public health, sanitary education, growth, and juvenile delinquency. There were also observers from a number of political organizations. Scientific communications seem to have been concerned with correspondingly diffuse subject matter, without much integration, although the abstracts (in French and English) are too brief to provide much more than main headings. Valuable as this volume should prove as a memento for those fortunate enough to have attended the congress, it is unlikely to be of profit to a wider public, unless perhaps for the useful bibliography that concludes it.

Le Nouveau-né-Directives Therapeutiques Medico-chirurgicales. By MARCEL FÉvre. (Pp. 190; Fr. fr. 2,500.) Paris: G. Doin et Cie. 1959.

This book is written for children's physicians by a surgeon, with the intention of showing them the indications for surgical intervention in the newborn. The author is professor of paediatric and orthopaedic surgery in the faculty of medicine in Paris and has already written a book about paediatric surgery for surgeons.

It is obvious on reading the book that he is a surgeon of wide experience and considerable skill. He keeps admirably to his self-imposed limits and does not discuss details of technique of no interest to physicians. The chapters cover conditions requiring immediate treatment, birth injuries, visible congenital defects, internal congenital defects, disorders of the post natal period and resuscitation. A wide range of conditions is covered in considerable detail. The methods described are modern and in most cases similar to those used in Britain; the chapter on intestinal obstruction is particularly good. The chief defect in the book is the lack of illustrations, necessary for the rare conditions described. There are a few adequate diagrams and a handful of very bad photographs. The book is paper-backed and uncut. The type used is admirable and there is a good index. The author deliberately limits his references to 18 standard works, although he names many more authors in the text (including 'Grey and Turner'!).

This is a good and unusual book which requires little knowledge of the French language and will provide all paediatric physicians with a good deal of new information.

Paediatric Tutorials: The Newly Born Infant. By ANDrew Bogdan. (Pp. 38; 3s.) Available from Anstick's Medical Bookshop, 53 Great George Street, Leeds 1, and other medical bookshops.

Dr. Bogdan has constructed a small notebook to be used at the cot-side. The main headings are filled in which deal with the normal and sick infant and ample blank pages are included for the student to make his own notes. 